\title{
1 Self-powered perovskite/CdS heterostructure photodetectors
}

2 Zibo Li, ${ }^{\dagger}$ Henan Li, ${ }^{* \S}$ Ke Jiang, ${ }^{\dagger}$ Dong Ding, ${ }^{\dagger}$ Jieni Li,${ }^{\dagger}$ Chun Ma,${ }^{\perp}$ Shangchi Jiang, $"$ Ye Wang, ${ }^{\#}$

3 Thomas D. Anthopoulos, ${ }^{\perp}$ Yumeng Shi*广+

4 International Collaborative Laboratory of 2D Materials for Optoelectronics Science and 5 Technology of Ministry of Education, Institute of Microscale Optoelectronics, Shenzhen 6 University, Shenzhen 518060, China.

$\S$ Institute of Microscale Optoelectronics, Shenzhen University, Shenzhen 518060, China.

Email: henan.li@szu.edu.cn

10

${ }^{\perp}$ King Abdullah University of Science and Technology (KAUST), KAUST Solar Center, Thuwal 23955-6900, Kingdom of Saudi Arabia.

13 Email:thomas.anthopoulos@kaust.edu.sa

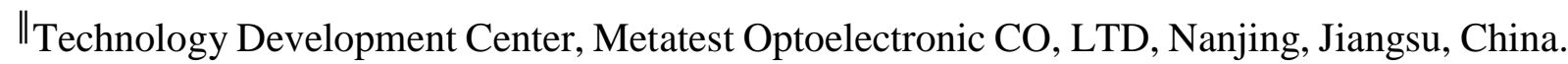

\#Key Laboratory of Material Physics of Ministry of Education, School of Physics and

Engineering, Zhengzhou University, Zhengzhou 450052, China

Engineering Technology Research Center for 2D Material Information Function Devices and Systems of Guangdong Province, Institute of Microscale Optoelectronics, Shenzhen University, Shenzhen 518060, China.

Email:yumeng.shi@szu.edu.cn

KEYWORDS. perovskite, photodetector, photovoltaic, heterojunction, photoconductive atomic force microscopy, self-powered photodetectors. 
1 Methylammonium lead halide perovskites have attracted enormous attention due to their

2 remarkable physical properties and potential for numerous (opto)electronic applications. Here,

3 high-performance photodetectors based on $\mathrm{CH}_{3} \mathrm{NH}_{3} \mathrm{PbI}_{3}\left(\mathrm{MAPbI}_{3}\right) / \mathrm{CdS}$ heterostructures, are

4 demonstrated. The resulting self-powered $\mathrm{MAPbI}_{3} / \mathrm{CdS}$ photodetectors show excellent

5 operating characteristics including a maximum detectivity of $2.3 \times 10^{11}$ Jones, responsivity of

$6 \quad 0.43 \mathrm{~A} / \mathrm{W}$ (both measured at $730 \mathrm{~nm}$ ) and temporal response time of $<14 \mathrm{~ms}$. The mechanisms

7 of charge separation and transport at the interface of the $\mathrm{MAPbI}_{3} / \mathrm{CdS}$ junction were 8 investigated via conductive and photoconductive atomic force microscopy (C-AFM and PC-

9 AFM). Obtained results show that grain boundaries exhibit higher photocurrent than flat regions

10 of the top perovskite layer, which indicates that excitons preferentially separate at the edges of

11 the perovskite crystals i.e. at the grain boundaries. The study of the photoelectric mechanism at

12 the nanoscale provides essential insights for the fabrication of high-performance perovskite13 based photodetectors, where the device performance could potentially be fine tuned through

14 grain boundary engineering. The demonstrated self-powered photodetector are promising for 15 numerous applications in low-energy consumption optoelectronic devices.

16

17

INTRODUCTION 
1 Methylammonium lead trihalide perovskite materials $\left(\mathrm{MAPbX}_{3}, \mathrm{MA}=\mathrm{CH}_{3} \mathrm{NH}_{3}{ }^{+} ; \mathrm{X}=\right.$ halogen $)$

2 have drawn increasing attention due to their long diffusion lengths, high light absorption

3 coefficients and low intergap trap density. ${ }^{1-3}$ In the past several years, hybrid perovskites were

4 shown great promise for photovoltaic applications where the power conversion efficiency

5 (PCE) of $\mathrm{MAPbX}_{3}$ based solar cells (PSCs) has increased from $3.8 \%$ to over $22.1 \% .^{4-7}$ In

6 addition, high-quality perovskite films can be synthesized via several rapid and simple methods,

7 such as spin coating, ${ }^{8}$ spray coating, ${ }^{9,10}$ slit-casting ${ }^{11}$ and blade coating, ${ }^{12-15}$ which can be

8 adapted to large-scale fabrication. These merits including simple fabrication processing and

9 outstanding optoelectronic properties make perovskites the most promising amongst emerging

10 photovoltaic technologies. More recently, the use of $\mathrm{MAPbX}_{3}$ perovskites has been extended

11 to photodetectors, i.e. devices that convert incident optical signals to electrical signals that are

12 key components for numerous modern applications, hence paving the way to new research directions. ${ }^{16,17}$

14 Numerous recent studies have revealed that the performance of photovoltaic cells is highly dependent on the interfacial properties between the electron transport layer (ETL) and the perovskite. ${ }^{18-20}$ An ideal ETL should provide conformal contact with the perovskite film and reduce the concentration of surface defects/traps. ${ }^{21-27}$ Moreover, the existence of a built-in potential at the heterointerface is desirable as it can effectively suppress the carrier recombination. ${ }^{28}$ Therefore, identifying suitable ETL systems is important for improving the performance of both solar cells and photodetectors. To this end, CdS is a well studied n-type semiconductor for solar cells and photodetectors with suitable energy band structure aligned with $\mathrm{CH}_{3} \mathrm{NH}_{3} \mathrm{PbI}_{3}\left(\mathrm{MAPbI}_{3}\right){ }^{29}$ Compared to other widely used ETL materials such as $\mathrm{TiO}_{2}$,

23 CdS shows significant higher electron mobility, ${ }^{30}$ and unlike $\mathrm{TiO}_{2}$ it dosen't suffer from oxygen vacancies-induced charge traps caused upon illumination with ultraviolet light. ${ }^{31-33}$ Previously,

PSCs. However, the CdS electron layer introduces a huge resistance, and consequently results 
1 in a low fill factor and the PCE is only $1.53 \% .{ }^{30}$ Similarly, Hwang et al. have used thermally

2 evaporated CdS as ETLs in PSCs with significantly higher PCE of $12.2 \% .{ }^{34}$ In their work CdS

3 PSC performed enhanced photostability (maintained $91 \%$ of its initial efficiency) under

4 continuous sunlight illumination for $12 \mathrm{~h}$, while the traditional $\mathrm{TiO}_{2}$ based PSC lost $82 \%$ of its

$5 \quad$ initial efficiency. Finally, in order to improve the crystallinity Peng et al. employed chemical

6 bath deposited (CBD) CdS as ETLs in PSC. The CdS PSC showed improved open-circuit

7 voltage with PCE of $16.1 \% .^{35}$

8 Here, heterostructured photodetector based on $\mathrm{CdS}$ and $\mathrm{MAPbI}_{3}$ perovskite were fabricated

9 and studied. The resulting devices showed excellent performance, with maximum on/off current

10 ratio of $\sim 1.13 \times 10^{5}$ (at $0 \mathrm{~V}$ ), specific detectivity of $\sim 9.79 \times 10^{10}$ Jones (at $0 \mathrm{~V}$ ) and PCE of

$11 \sim 10.05 \%$. The role of $\mathrm{CdS}$ on the charge photogeneration and transport across in the

$12 \mathrm{MAPbI}_{3} / \mathrm{CdS}$ heterojunction was thoroughly studied using conductive and photoconductive

13 atomic force microscopy (C-AFM and PC-AFM) ${ }^{36-40}$ The work highlights $\mathrm{MAPbI}_{3} / \mathrm{CdS}$ as a

14 promising heterojunction for various emerging applications.
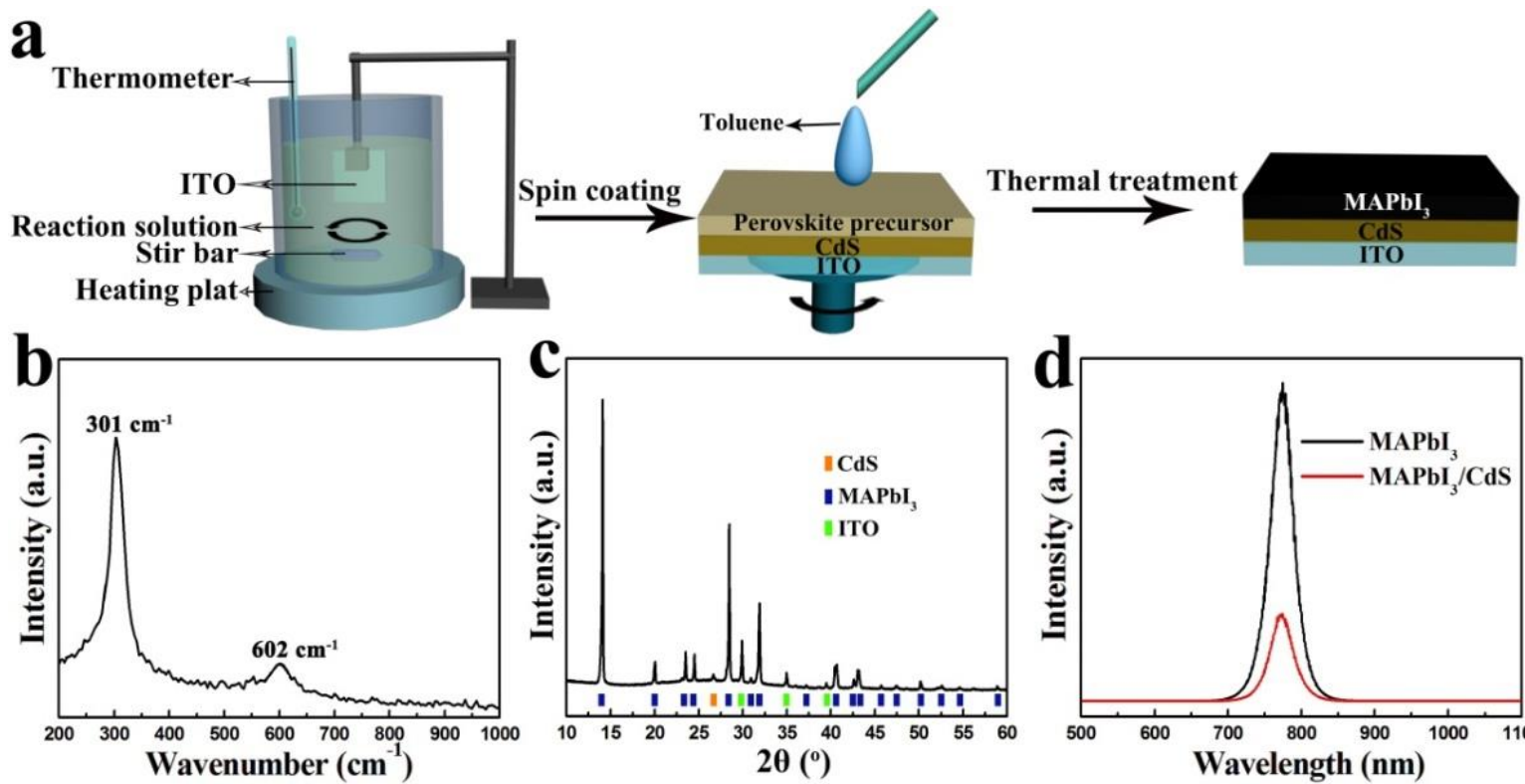

Figure 1. (a) Schematic illustration of the fabrication process of $\mathrm{MAPbI}_{3} / \mathrm{CdS}$ heterojunction.

(c) XRD spectra of the $\mathrm{MAPbI}_{3} / \mathrm{CdS}$ heterojunction. (d)

$$
\mathrm{PL} \text { spectra of pure } \mathrm{MAPbI}_{3} \text { film and } \mathrm{MAPbI}_{3} / \mathrm{CdS} \text { heterojunction. }
$$


Preparation of $\mathrm{MAPbI}_{3} / \mathrm{CdS}$ Bilayer. Figure 1a shows the fabrication process of the

$2 \mathrm{MAPbI}_{3} / \mathrm{CdS}$ heterojunction. The $\mathrm{CdS}$ was grown via CBD method (Figure 1a). The thickness

3 of the CdS film can be tuned by changing the deposition time. Figure $1 \mathrm{~b}$ displays the Raman

4 spectra of a representative CdS layer. The Raman peak at $301 \mathrm{~cm}^{-1}$ originates from the $\mathrm{A}_{1}(\mathrm{LO})$

5 mode (where LO stands for longitudinal optical phonon) and its overtone at $602 \mathrm{~cm}^{-1}$ proving

6 the successful synthesis of CdS. ${ }^{41}$

$7 \quad \mathrm{MAPbI}_{3}$ was then deposited atop CdS via one-step spin-coating method (Figure 1a). X-ray diffraction (XRD) measurements were also performed and provided further evidence of the presence of the CdS and $\mathrm{MAPbI}_{3}$ when deposited on ITO (Figure 1c). The diffraction peaks of CdS indium tin oxide (ITO) (transparent electrode), ${ }^{28}$ and $\mathrm{MAPbI}_{3 .}{ }^{42,43}$ are indicated by the 11 yellow, green and blue bars, ${ }^{41}$ respectively. None of the $\mathrm{PbI}_{2}$ peaks were observed in the $\mathrm{XRD}$ 12 data, indicating the good quality of $\mathrm{MAPbI}_{3}$ layer.

Figure 1d exhibits the PL spectra for the $\mathrm{MAPbI}_{3}$ and $\mathrm{MAPbI}_{3} / \mathrm{CdS}$ heterojunction excited using a $532 \mathrm{~nm}$ laser. Both samples show strong PL signal with peak at $778 \mathrm{~nm}$ which is consistent with the PL feature of pristine $\mathrm{MAPbI}_{3} .{ }^{44,45}$ However, the intensity of the PL signal of the $\mathrm{MAPbI}_{3} / \mathrm{CdS}$ heterojunction was significantly lower than that for the pristine $\mathrm{MAPbI}_{3}$. This dramatic PL reduction is attributed to the efficient charge transfer occurring between the metal halide perovskite and $\mathrm{CdS},{ }^{24,26}$ and will be discussed next.
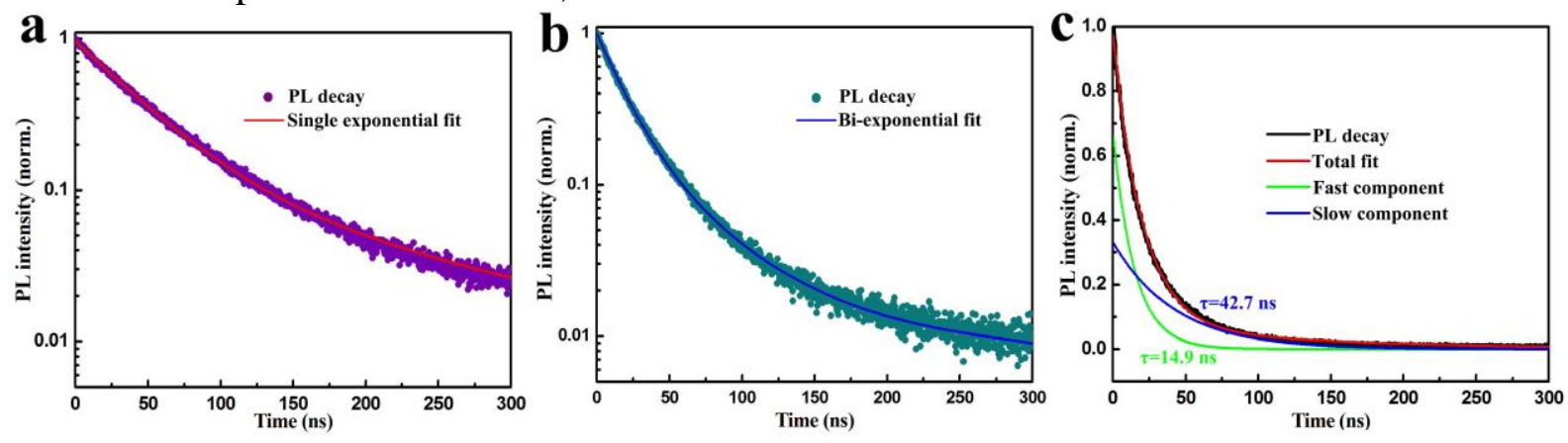

Figure 2. The time resolved PL decay curves. (a) $\mathrm{MAPbI}_{3}$ film. (b) $\mathrm{MAPbI}_{3} / \mathrm{CdS}$ bilayer. (c)

The time resolved PL decay curves of $\mathrm{MAPbI}_{3} / \mathrm{CdS}$ bilayer with biexponential fits showing a

fast $(\mathrm{t} \approx 14.9 \mathrm{~ns})$ and a slow transient $(\mathrm{t} \approx 42.7 \mathrm{~ns})$. 
In an effort to better understand the charge carrier dynamics at the $\mathrm{MAPbI}_{3} / \mathrm{CdS}$

2 heterointerface, time-resolved PL measurements were performed (Figure 2). The time-resolved

3 traces represent the transient evolution of the electron-hole population after impulsive

4 photoexcitation, and the measured transient decay process of the excited state can be fitted

5 using:

$$
\mathrm{I}_{(\mathrm{t})}=\mathrm{I}_{0} \sum_{i} w_{i} \exp \left(-\frac{\mathrm{t}}{\tau_{i}}\right)
$$

7 where $\mathrm{I}_{0}$ is the initial intensity, $w_{\mathrm{i}}$ is $\mathrm{i}^{\text {th }}$ amplitude, $\tau_{\mathrm{i}}$ is the lifetime. ${ }^{46}$ As shown in Figure $2 \mathrm{a}$, $8 \mathrm{i}=1$ was utilized for the pristine $\mathrm{MAPbI}_{3}$ due to its single exponential decay. The fitting yields

9 a lifetime of $43.5 \mathrm{~ns}$, which is close to previously reported values. ${ }^{47,48}$ For the $\mathrm{MAPbI}_{3} / \mathrm{CdS}$ 10 heterojunction as shown in Figure 2b, the charge carrier lifetime decreased obviously and 11 biexponential decay, where $\mathrm{i}=2$, was used for the fitting. Analysis of the fitting in Figure $2 b$ 12 yields times for the fast part of the decay of $14.9 \mathrm{~ns}$ and $42.7 \mathrm{~ns}$ for the slower part as shown in 13 Figure 2c. These times are attributed to the different lifetimes of photocarriers on the surface 14 and in the bulk, respectively. ${ }^{49,50}$ To this end, the faster PL decay indicates efficient charge 15 transfer at the heterointerface ${ }^{51}$ in agreement with the significantly quenched PL signal seen in 16 Figure 1d. On the basis of this data we conclude that the formed $\mathrm{MAPbI}_{3} / \mathrm{CdS}$ heterointerface 17 promotes efficient charge transfer. ${ }^{52}$

$\mathbf{a}$
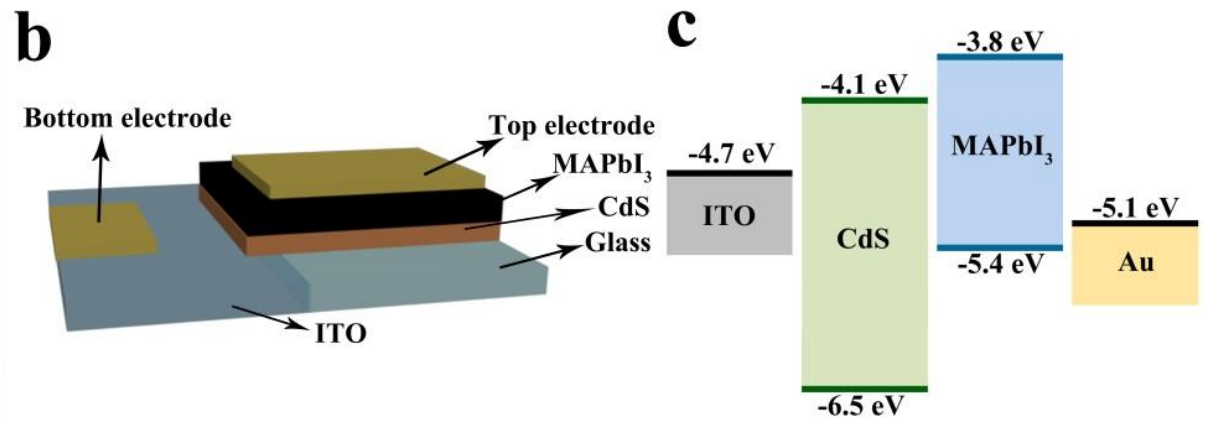

Figure 3. (a) Photograph of the photodetector made by $\mathrm{MAPbI}_{3} / \mathrm{CdS}$ heterojunction. (b)

3 Schematic diagram of the device. (c) Energy band diagram of the $\mathrm{MAPbI}_{3} / \mathrm{CdS}$ heterojunction photodetector. 
Fabrication of $\mathrm{MAPbI}_{3} / \mathrm{CdS}$ Heterojunction Photodetector. Photodetector devices

2 consisting of $\mathrm{ITO} / \mathrm{CdS} / \mathrm{MAPbI}_{3} / \mathrm{Au}$ (Figure 3a-b), were fabricated with the $\mathrm{CdS}$ layer

3 functioning as the ETL. Reference devices based on $\mathrm{MAPbI}_{3}$-only and CdS-only were also

4 prepared in parallel (see Figure S1). Optimal device performance was achieved by carefully

5 tuning the thickness of $\mathrm{CdS}$ and $\mathrm{MAPbI}_{3}$ layers as shown in Figures $\mathrm{S} 2$ and $\mathrm{S} 3$ (relevant

6 discussion in Note $\mathrm{S} 1$ ). The optimum thicknesses of $\mathrm{CdS}$ and $\mathrm{MAPbI}_{3}$ were determined to be

$7 \sim 55 \mathrm{~nm}$ and $\sim 378 \mathrm{~nm}$, respectively. From the energy band diagram in Figure $3 \mathrm{c}$, the conduction band of $\mathrm{CdS}$ is $\sim 0.3 \mathrm{eV}$ lower than that of $\mathrm{MAPbI}_{3}$. This large energy offset suggests that the

CdS ETL can indeed accept electrons that eventually be transported to the ITO electrode, while simultaneously blocking holes at the $\mathrm{MAPbI}_{3} / \mathrm{CdS}$ interface. ${ }^{53}$ These results are in excellent 11 agreement with the PL data shown in Figure 1d and Figure 2b.

Measurements of the Device Performance. The built-in field presents at the $\mathrm{MAPbI}_{3} / \mathrm{CdS}$ interface (Figure $3 b$ ) is expected to enhance the photoresponse of the detector. In Figure 4a, we present the I-V curves of the $\mathrm{MAPbI}_{3} / \mathrm{CdS}$ photodetectors measured in the dark and under various white light illumination intensities with the corresponding linear I-V curves shown in Figure S4a. The device based on the $\mathrm{MAPbI}_{3} / \mathrm{CdS}$ heterointerface show clear photovoltaic action with an open circuit voltage $\sim 0.75 \mathrm{~V}$. Moreover, the photocurrent is significantly increased as compared to the $\mathrm{MAPbI}_{3}$-only device shown in Figure $4 \mathrm{~b}$ (the linear dark I-V curves are shown in Figure S4b). It should be noted that the CdS-only device shows much weaker photocurrent compared with $\mathrm{MAPbI}_{3}$-only device (Figure S5). Therefore, the enhanced photocurrent measured for the $\mathrm{MAPbI}_{3} / \mathrm{CdS}$ device can be attributed to the efficient charge separation at the $\mathrm{MAPbI}_{3} / \mathrm{CdS}$ heterointerface, in excellent agreement with the afore mentioned PL results.

Responsivity $(R)$ and detectivity $(D)$ are the two important parameters used to evaluate the performance of the photodetector. The responsivity of the detector can be obtained using: 
2

4
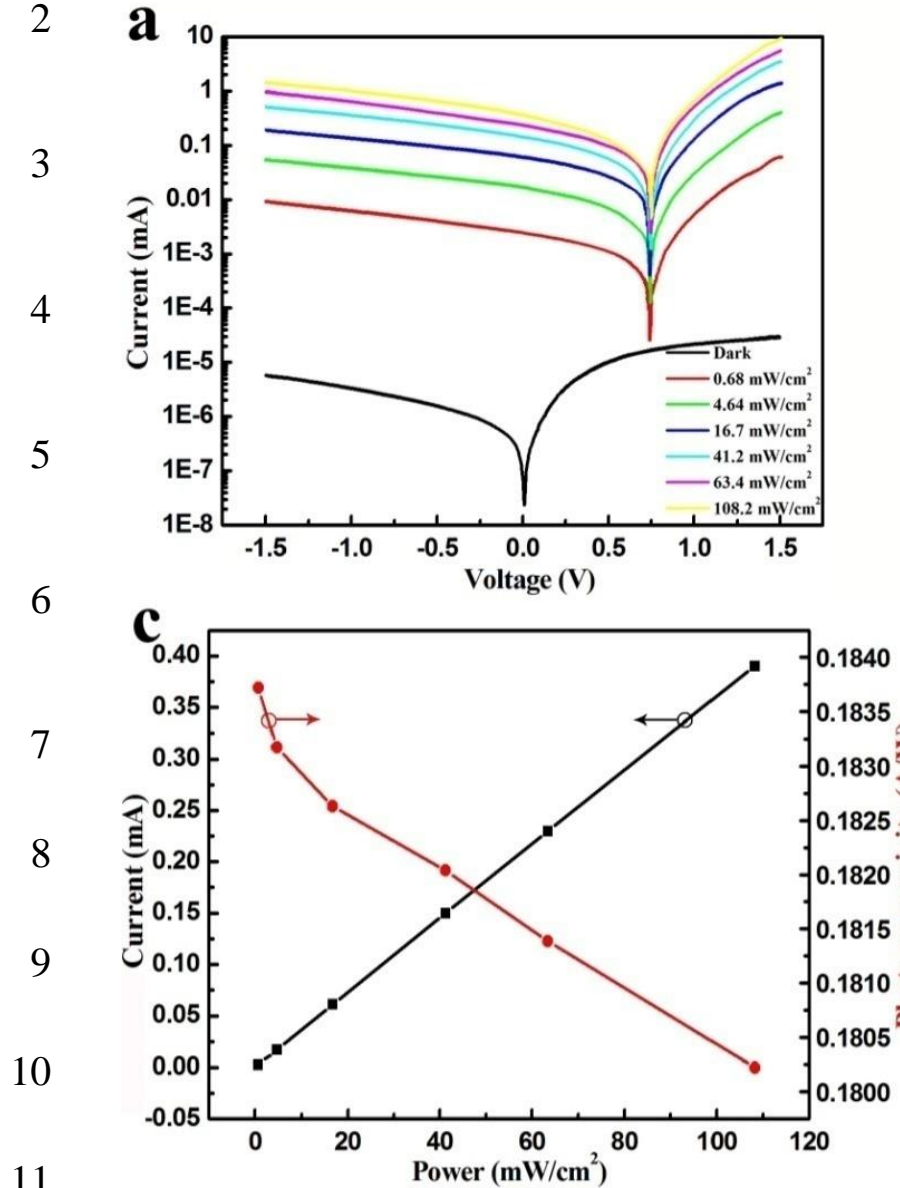

11

12

13

14

15

16

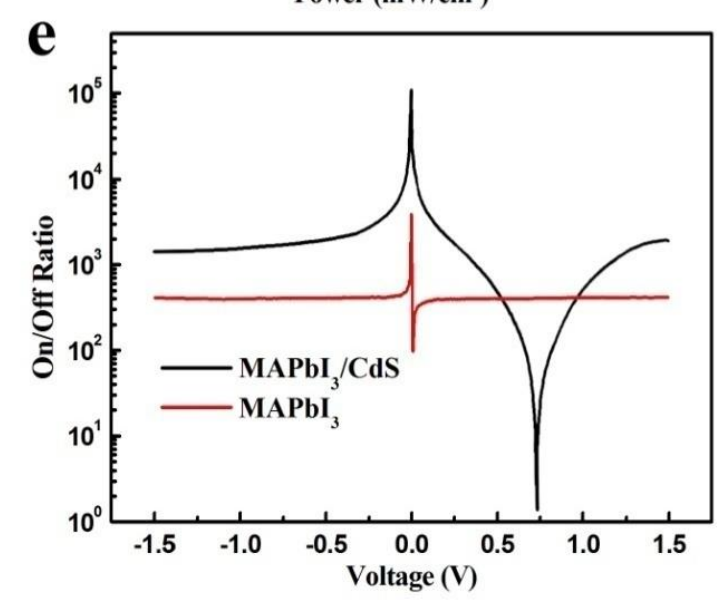

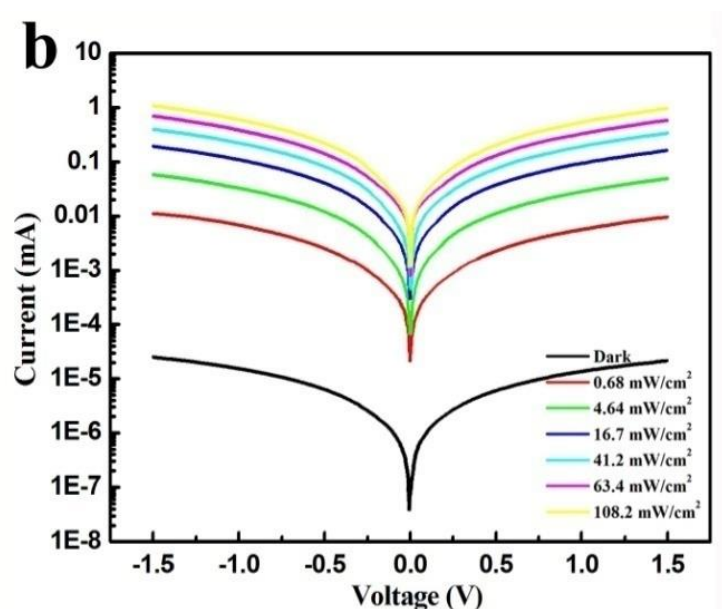
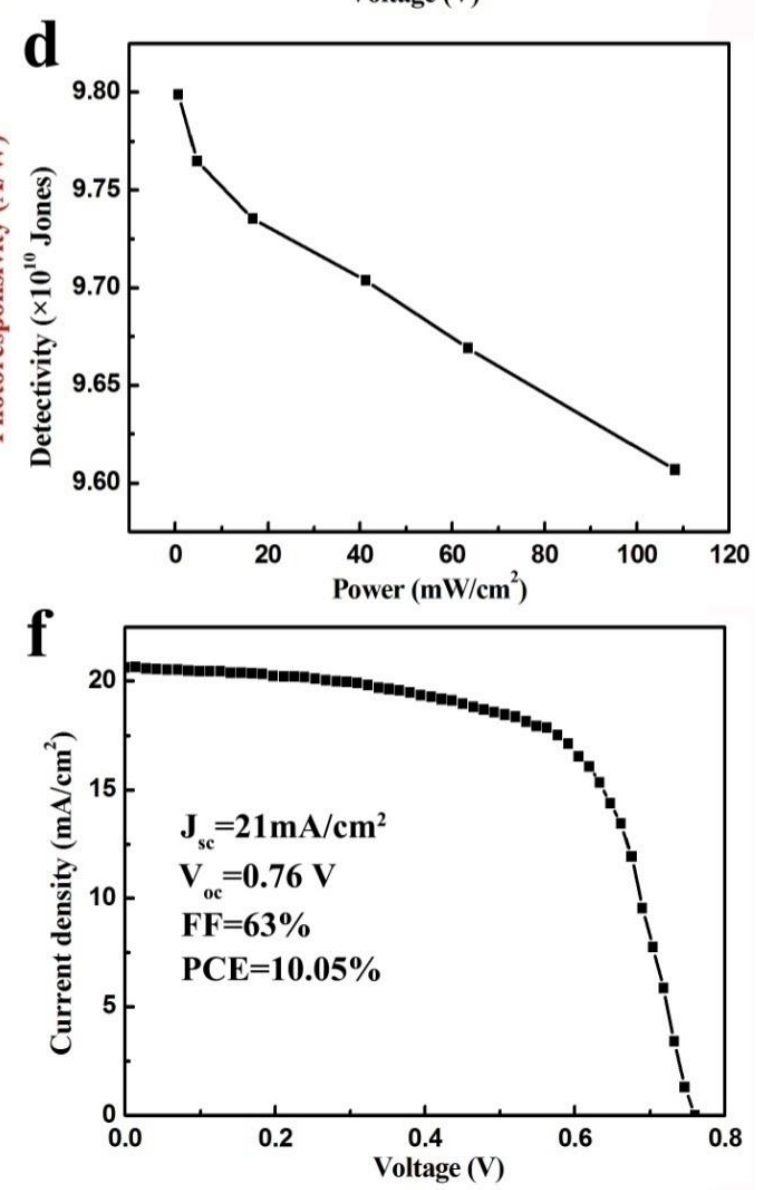
2 Figure 4. (a) I-V curves of the heterojunction photodetector in dark and under different 3 illumination intensities. (b) Corresponding I-V curves of $\mathrm{MAPbI}_{3}$-only device. (c) Photocurrent 4 and photoresponsivity of the heterojunction photodetector measured under 0 V. (d) Detectivity 5 of the $\mathrm{MAPbI}_{3} / \mathrm{CdS}$ photodetector under $0 \mathrm{~V}$. (e) On/off ratios measured on different voltages of $\mathrm{MAPbI}_{3} / \mathrm{CdS}$ photodetector and $\mathrm{MAPbI}_{3}$-only device. (f) $\mathrm{J}-\mathrm{V}$ characteristics of the $\mathrm{MAPbI}_{3} / \mathrm{CdS}$ photodetector under simulated AM $1.5 \mathrm{G}$ solar irradiation.

$$
\mathrm{R}=\frac{\mathrm{I}_{\text {Photo }}-\mathrm{I}_{\text {Dark }}}{\mathrm{P}_{\text {in }} * \mathrm{~A}}
$$

9 where $P_{\text {in }}$ is incident light intensity, $I_{\text {dark }}$ is the dark current and $I_{\text {photo }}$ is the measured 10 photocurrent. ${ }^{54}$ The noise current and noise equivalent power were also measured in order to 11 evaluate the photodetector performance (see Note S2 and Figure S6). Through the analysis of the noise current, the specific detectivity can be evaluated using:

$$
\mathrm{D}=\frac{\mathrm{R} \sqrt{\mathrm{A}}}{\sqrt{2 \mathrm{qI}_{\mathrm{Dark}}}}
$$

where $\mathrm{q}$ is elementary charge and $\mathrm{A}$ is the active area $\left(0.02 \mathrm{~cm}^{2}\right)$ of the device..$^{55}$

Figure $4 \mathrm{c}-\mathrm{d}$ show the photocurrent, photoresponsivity and detectivity of the $\mathrm{MAPbI}_{3} / \mathrm{CdS}$ photodetector evaluated at $0 \mathrm{~V}$. For comparison, the same parameters measured at $1.5 \mathrm{~V}$ are also presented in Figure S7. Under illumination intensity of $0.68 \mathrm{~mW} / \mathrm{cm}^{2}$, the $\mathrm{MAPbI}_{3} / \mathrm{CdS}$ photodetector exhibits a responsivity of $0.183 \mathrm{~A} / \mathrm{W}$ under $0 \mathrm{~V}$ and $4.45 \mathrm{~A} / \mathrm{W}$ at $1.5 \mathrm{~V}$. The detectivity measured under illumination intensity of $0.68 \mathrm{~mW} / \mathrm{cm}^{2}$ for the $\mathrm{MAPbI}_{3} / \mathrm{CdS}$ photodetector is $9.79 \times 10^{10}$ Jones at $0 \mathrm{~V}$, and reduces to $6.36 \times 10^{10}$ Jones at $1.5 \mathrm{~V}$ due to increased $\mathrm{I}_{\mathrm{dark}}$. Figure $4 \mathrm{e}$ exhibits the bias dependence of current on/off ratio. At a bias voltage of $\sim 0 \mathrm{~V}$, the on/off ratio reaches the highest value of $1.13 \times 10^{5}$ under $0.68 \mathrm{~mW} / \mathrm{cm}^{2}$ light illumination. When the $\mathrm{MAPbI}_{3} / \mathrm{CdS}$ heterojunction device was operated as a solar cell (fourth quadrant of the I-V curves), a power conversion efficiency of $10.05 \%$ was calculated under 100 $\mathrm{mW} / \mathrm{cm}^{2} \mathrm{AM} 1.5$ simulated solar radiation (Figure 4f), which demonstrates the self-powered 
1 performance of the $\mathrm{MAPbI}_{3} / \mathrm{CdS}$ heterojunction device. A higher PCE could be reached by

2 carefully selecting suitable hole transport layers that assist the hole-electron pair separation and

3 charge extraction.

4 The I-V curves measured under different illumination wavelengths in the range of 405-850

$5 \mathrm{~nm}$ and at a constant illumination power of $10 \mathrm{~mW} / \mathrm{cm}^{2}$ for a representative $\mathrm{MAPbI}_{3} / \mathrm{CdS}$

6 photodetector, are shown in Figure 5a. Figure 5b shows the ultraviolet-visible (UV-Vis)

7 absorption spectra of the $\mathrm{CdS}$ film, perovskite film and $\mathrm{MAPbI}_{3} / \mathrm{CdS}$ hybrid system. When the

$8 \mathrm{MAPbI}_{3} / \mathrm{CdS}$ photodetector is excited with light of 405, 488, 550, 610 and $715 \mathrm{~nm}$, the

9 photocurrent of the $\mathrm{MAPbI}_{3} / \mathrm{CdS}$ photodetector is clearly enhanced as compared to the dark

current. Interestingly, no obvious increase in the photocurrent upon excitation at $850 \mathrm{~nm}$ is

11 observed in line with the absorption spectrum of the $\mathrm{MAPbI}_{3} / \mathrm{CdS}$ hybrid system (Figure $5 \mathrm{~b}$ ).

12 Since CdS has a bandgap $~ 2.4 \mathrm{eV}$ (Figure 3c), absorption should only occur at wavelengths shorter than $520 \mathrm{~nm}$. Indeed, the introduction of CdS enhances the absorption region of $\mathrm{MAPbI}_{3}$ film especially from $350 \mathrm{~nm}$ to $523 \mathrm{~nm}$ as shown in Figure 5b. As shown in Figure 5c, the $\mathrm{MAPbI}_{3} / \mathrm{CdS}$ device yields a relatively high external quantum efficiency (EQE) of over $65 \%$ in the $360-630 \mathrm{~nm}$ range. Meanwhile, the drop-off in the EQE curve above $800 \mathrm{~nm}$ indicates that the photons with wavelength longer than $800 \mathrm{~nm}$ are not efficiently absorbed. Figure 5c and Figure S8 show the responsivity (green line) and detectivity for the device. The responsivity can be calculated by the relationship: $\mathrm{EQE}=R \times \mathrm{E} \times 100$, where $\mathrm{E}$ is the incident photon energy. On the other hand, $D$ can be obtained by using Eq. 3. For illumination 21 wavelengths over $800 \mathrm{~nm}$, both the $R$ and $D$ exhibit a significant drop. The maximum values of $22 D$ and $R$ are $2.3 \times 10^{11}$ Jones and $0.43 \mathrm{~A} / \mathrm{W}$, respectively, measured at $730 \mathrm{~nm}$ under $10 \mathrm{~mW} / \mathrm{cm}^{2}$ 23 illumination intensity.
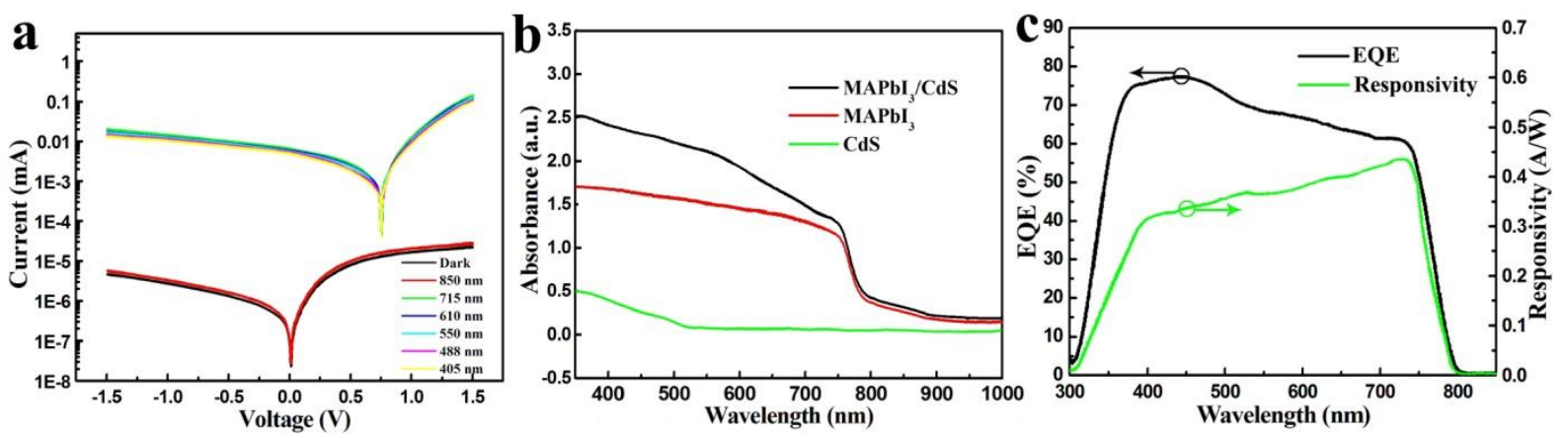
Figure 5. (a) I-V curves under different illumination wavelengths. (b) UV-VIS absorption spectra of the pure $\mathrm{CdS}$ film, pure $\mathrm{MAPbI}_{3}$ film and $\mathrm{MAPbI}_{3} / \mathrm{CdS}$ hybrid films. (c) $\mathrm{EQE}$ and responsivity of $\mathrm{MAPbI}_{3} / \mathrm{CdS}$ photodetector.

Finally, the temporal response of the heterojunction $\mathrm{MAPbI}_{3} / \mathrm{CdS}$ photodetector to white light pulses $\left(40 \mathrm{~mW} / \mathrm{cm}^{2}\right)$ was investigated. Figure 6 exhibits the time dependence photoresponse of the device biased at $1.5 \mathrm{~V}$. Figure 6a shows that the light-induced on/off switching is consistent and repeatable over multiple cycles. Figure $6 \mathrm{~b}$ shows one cycle of the temporal photoresponse, from which the rise and decay times were calculated yielding 3.2 and $9.6 \mathrm{~ms}$, respectively. Evidently, the temporal photoresponse of the $\mathrm{MAPbI}_{3} / \mathrm{CdS}$ photodetector is faster than that of $\mathrm{MAPbI}_{3}$-only and CdS-only device. We ascribe this to the efficient charge transfer at the heterointerface. In terms of response speed, we note that our $\mathrm{MAPbI}_{3} / \mathrm{CdS}$ photodetector is approximately three orders of magnitude faster than the perovskite/graphene photodetector reported previously, ${ }^{56}$ and one order of magnitude faster than state-of-art nanostructured perovskite photodetector. ${ }^{57}$ The only faster metal halide perovskite photodetector reported to date is the recently demonstrated nano-gap photodetectors by Georgiadou et al., ${ }^{58}$ where the transit time of the photogenerated charge carriers was substantially reduced owing to the nanoscale interelectrode distance. Despite that, our proposed $\mathrm{MAPbI}_{3} / \mathrm{CdS}$ photodetector concept offer numerous advantages including high responsivity, specific detectivity and high self-powered performance with the potential for further improvements.
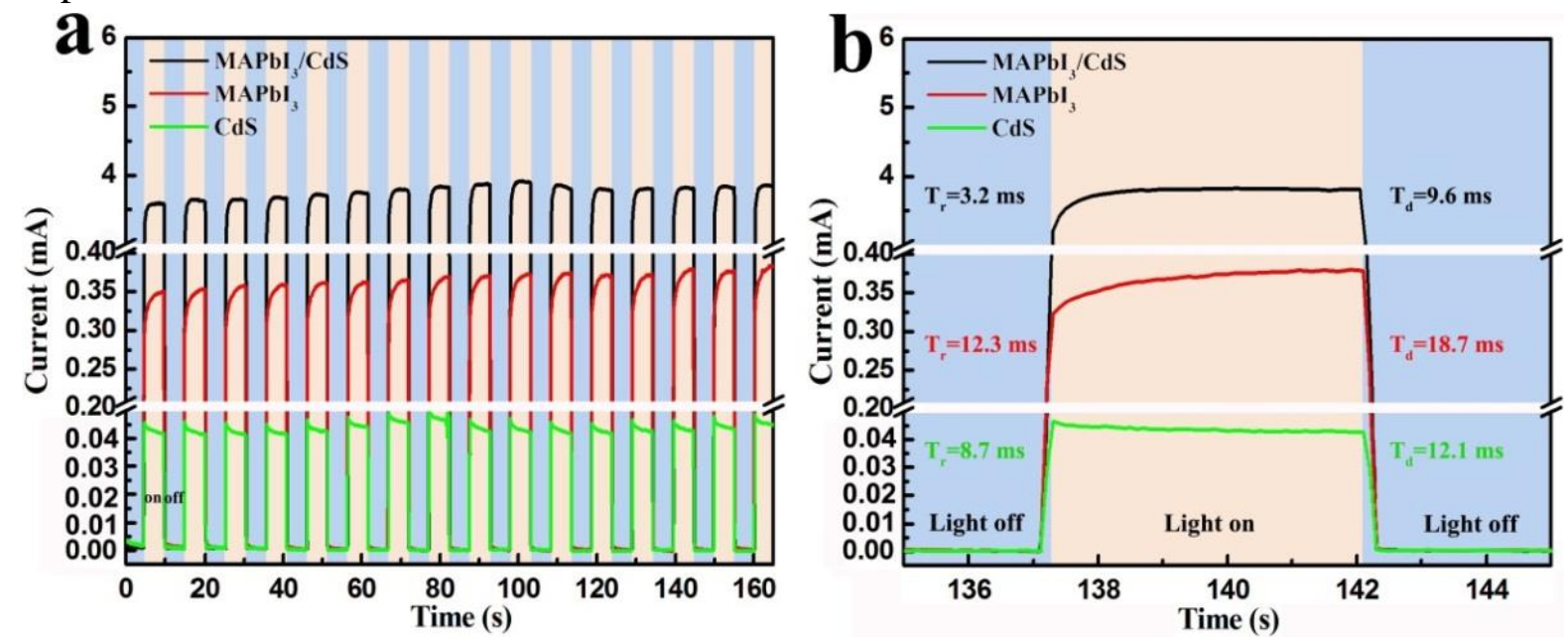

Figure 6. (a) Photoswitching characteristics of the three types of photodetectors under chopped light irradiation. (b) Temporal photocurrent response for the three types of photodetectors. 
2 promising potential of the $\mathrm{MAPbI}_{3} / \mathrm{CdS}$ heterojunction, we further explored the photoelectric

3 mechanism of $\mathrm{MAPbI}_{3} / \mathrm{CdS}$ heterojunction using C-AFM and PC-AFM techniques. Photo-

4 current mapping using these techniques can provide valuable information regarding the

5 relationship between the heterojunction morphology and charge transport in the nanoscale. ${ }^{36-40}$

6 Figure 7a shows the schematic diagram of the C-AFM and PC-AFM setups. A Pt-Ir-coated tip

7 was used for C-AFM and PC-AFM measurements. The ITO was then biased with a voltage

8 while the conductive AFM tip was grounded.

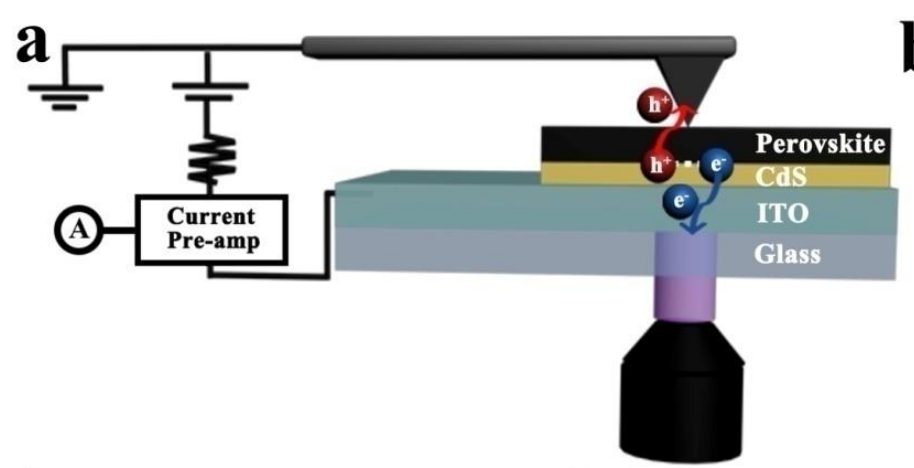

b
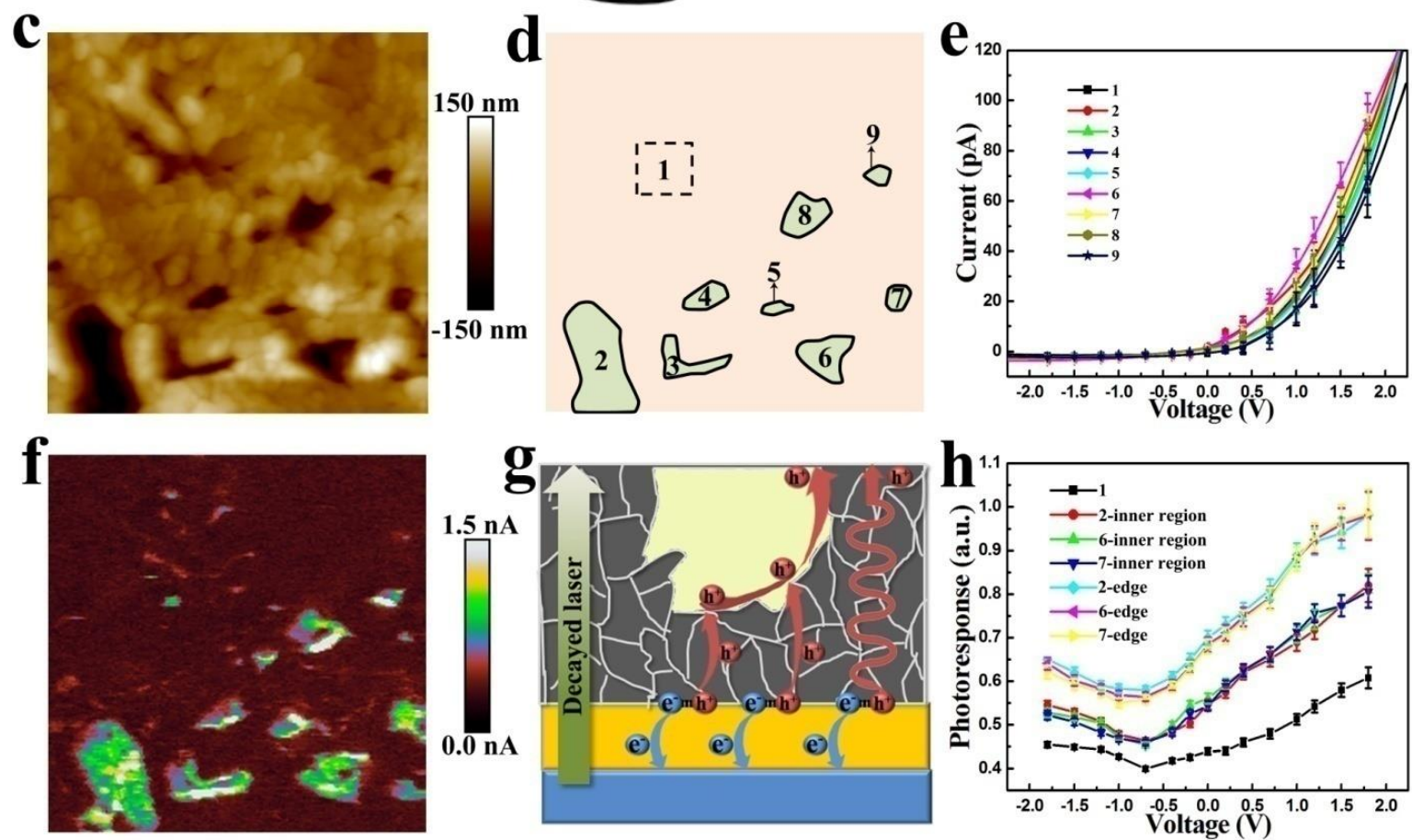

Figure 7. (a) Schematic illustration of the PC-AFM instrument. (b) Energy band diagram of the tip, $\mathrm{MAPbI}_{3}, \mathrm{CdS}$ and ITO. (c) AFM topographic image of $\mathrm{MAPbI}_{3} / \mathrm{CdS}$ heterojunction. (d) Schematic illustration of the $\mathrm{MAPbI}_{3} / \mathrm{CdS}$ surface with cavities as shown in image c. (e)

40 Fitting I-V curves extracted at the regions 1-9 shown in d. (f) Image of photocurrent mapping. 
1 dependent photoresponse curves corresponding to region 1 and selected areas from interiors 2 and edges of region 2, 6 and 7.

3 A series of current maps were acquired under different applied voltages in the range of -1.8

$4 \mathrm{~V}$ to $+1.8 \mathrm{~V}$ (Figure S9). The brighter (darker) areas in the current mapping indicate the higher

5 absolute current under positive (negative) bias. The corresponding AFM topographic image is

6 shown in Figure 7c. We identify the presence of several cavities in the perovskite layer marked

7 as the nine regions shown in Figure $7 d$. Those cavities are formed by perovskite crystals with

8 exposed grain boundaries of perovskite crystals, allowing us to compare the spatial dependence

9 of photocurrent generation in the perovskite thin film. The point I-V curves measured from these nine regions are plotted in Figure 7e, with the error bars representing the standard

11 deviations. Due to the p-type nature of $\mathrm{MAPbI}_{3}$ and the n-type nature of $\mathrm{CdS}$ (Figure 7b), the

12 measured I-V curves exhibit $\mathrm{p} / \mathrm{n}$-like rectifying characteristic.

13 In an effort to understand the nature of the charge transport mechanism, the point I-V curves 14 were fitted with the thermionic emission model. Previously, Li et al. have used thermionic 15 emission to describe the carrier transport between $\mathrm{MoS}_{2}$ and an AFM tip ${ }^{59}$ :

$$
I=I_{0}\left[\exp \left(\frac{q V}{\eta k_{B} T}\right)-1\right]
$$

17 where $\mathrm{I}_{0}$ is the saturation current, $\mathrm{V}$ is the applied sample bias, $\mathrm{k}_{\mathrm{B}}$ is the Boltzmann constant, $\mathrm{q}$ 18 is the electronic charge, $\eta$ is the ideality factor, and $\mathrm{T}$ is the temperature. Alternatively, the 19 equation can also be presented as:

$$
\mathrm{I}_{0}=\mathrm{A}_{\mathrm{e}} \mathrm{A} * \mathrm{~T}^{2} \exp \left(-\frac{\mathrm{q} \Phi_{\mathrm{B}}}{\mathrm{K}_{\mathrm{B}} \mathrm{T}}\right)
$$

21 where $\mathrm{A}^{*}$ is the Richardson constant (defined in the Note S3), $\mathrm{A}_{\mathrm{e}}$ is the effective contact area 22 obtained by Hertz contact theory (Note S4 and Figure S10). 
As shown in Figure 7e, the current fittings suggest the carrier transport follows the thermionic emission theory very well. In addition, in thermionic emission theory, the barrier height $\Phi_{\mathrm{B}}$ can be determined using:

$$
\Phi_{\mathrm{B}}=\frac{\mathrm{k}_{\mathrm{B}} \mathrm{T}}{\mathrm{q}} \ln \left(\frac{\mathrm{A}^{*} \mathrm{~A}_{\mathrm{e}} \mathrm{T}^{2}}{\mathrm{I}_{0}}\right)
$$
nine regions marked in Figure $7 d$.

Table 1: $\Phi_{\mathrm{B}}$ of the eight cavities and flat region.

\begin{tabular}{|l|c|c|c|c|c|c|c|c|c|}
\hline Region & 1 & 2 & 3 & 4 & 5 & 6 & 7 & 8 & 9 \\
\hline$\Phi_{\mathrm{B}} / \mathrm{eV}$ & 0.85 & 0.80 & 0.78 & 0.76 & 0.79 & 0.82 & 0.79 & 0.77 & 0.74 \\
\hline
\end{tabular}

The value of $\Phi_{\mathrm{B}}$ for the eight cavities is consistently smaller than that of the flat region due to the short transport distance of the cavity area to the bottom of the $\mathrm{MAPbI}_{3} / \mathrm{CdS}$ interface. In addition, the ideality factor $\eta$ can be calculated using:

$$
\frac{1}{\eta}=\frac{\mathrm{k}_{\mathrm{B}} \mathrm{T}}{\mathrm{q}} \frac{d(\ln I)}{d V}
$$

where the value of $\eta$ can be used to estimate the deviation of carrier transport process from the ideal thermal emission. Herein, $\eta$ of the nine regions ranges from 5.35 to 5.86 (shown in Figure S11). The relatively high $\eta$ is likely attributable to non-idealities such as defects at the 17 perovskite surface. ${ }^{28}$

Study of the Photoelectric Mechanism in $\mathrm{MAPbI}_{3} / \mathrm{CdS}$ Heterojunctions. The sample regions highlighted in Figure 7d were also studied by PC-AFM in order to compare the charge transport with photocurrent characteristics. Figure S12 shows the photocurrent maps obtained

21 at different applied sample potentials measured under $405 \mathrm{~nm}$ laser illumination. The results reveal obvious current enhancement compared with the corresponding dark current at the same

23 voltage (see Figure S9). The photocurrent map under a bias voltage of $0.2 \mathrm{~V}$ is shown in Figure 
$17 f$. Interestingly, the photocurrent near the apparent cavities (indicated as regions 2-9 in Figure

2 7d) appears enhanced by several times compared with the flatter regions atop the perovskite

3 layer (region 1). The photocurrent around the edges of the cavities also appears higher.

4 We further analyzed the photoresponse from the inner area and edges of the cavities present 5 on the perovskite film. Figure S13 shows photoresponse mappings of the $\mathrm{MAPbI}_{3} / \mathrm{CdS}$ 6 heterostructure. Here, the photoresponse was defined as:

$$
\text { Photoresponse }=\frac{\left(\mathrm{I}_{\text {Photo }}-\mathrm{I}_{\text {Dark }}\right) / \mathrm{q}}{\mathrm{P}_{\text {in }} / \mathrm{h} v}
$$

where $I_{\text {Dark }}$ is dark current, IPhoto is photocurrent, $q$ is elementary charge, $P_{\text {in }}$ is the optical power and $\mathrm{h} v$ is the photon energy. The photoresponse images were then generated by NanoScopeAnalysis software package using Eq. 8.

11 The voltage dependent photoresponse curves were plotted by extracting the average photoresponse values from "region 1", and selected areas from interiors and edges of "region 2,6 , and 7" as shown in Figure $7 \mathrm{~h}$. All curves exhibit an open circuit voltage of $\sim 0.7 \mathrm{~V}$, where a minimum photoresponse value is obtained. This photovoltaic phenomenon agrees well with the results obtained from the I-V feature of $\mathrm{MAPbI}_{3} / \mathrm{CdS}$ photodetector mentioned above. These photoresponse curves rise linearly in the voltage range from $-0.7 \mathrm{~V}$ to $1.8 \mathrm{~V}$ due to the increasing of the forward voltage. Moreover, "hot spots" observed in the photocurrent image (Figure 7f) are distributed along the edges of the cavities, which indicates a high photoresponse for these specific edge areas. On the other hand, the flat region (region 1) exhibits the lowest photoresponse. It should be noted that tip convolution effects may play a role in the photocurrent mapping. For example, the conductive AFM tip could be in better contact with the edges than with the surface of the layer, leading to a larger contact area and as higher currents. In order to eliminate tip convolution effects, all the photocurrent mappings were obtained through superior force control of the AFM tip (PeakForce TUNA, Bruker). A pN-level tip-sample interaction force was applied for the PC-AFM experiments, which is significantly 
1 lower than typically used with tapping mode $(\sim 1 \mathrm{nN})$. The tip-sample interaction force is

2 measured directly by the deflection of the cantilever and the feedback loop keeps the peak force

3 constant during the photocurrent mappings, which enables direct, precise force control and

4 eliminates lateral forces. According to the AFM results, the maximum depth of the cavities is

$5 \sim 180 \mathrm{~nm}$, which is much less than the perovskite thickness $(\sim 380 \mathrm{~nm})$, demonstrating that the

$6 \mathrm{CdS}$ film was fully covered by the $\mathrm{MAPbI}_{3}$ film. Therefore, we infer that the short transport

7 distance of the cavity area from sample surface to the bottom of the $\mathrm{MAPbI}_{3} / \mathrm{CdS}$ interface resulted in higher photocurrent value compared with the flat region (region 1). Previously, it was shown that excitons can separate more efficiently at the edges of a perovskite crystal, and the photogenerated carriers preferentially transport along its grain boundaries. ${ }^{60,61}$ It is therefore 11 very likely that a similar process is at play here. The proposed transport mechanism of the photocarriers is illustrated in Figure $7 \mathrm{~g}$, where excitons preferentially separate at the grain boundaries of perovskite crystals and therefore the edges of the cavities exhibit higher photocurrent.

Spatial Analysis of Photocurrent Generation. Spatial analysis was performed on the topographic mapping and dark/photo current mappings to study the transport mechanism of photon-generated carriers. Figure S14a-c show the topographic, dark current and photocurrent images under $1.8 \mathrm{~V}$. The 2D fast Fourier transforms (FFTs) were conducted on these three mappings as shown in Figure S14d-f. The center of the topographic FFTs image (Figure S14d) exhibits the strongest intensity. However, the intensity of dark current FFTs image (Figure S14e) shows a dispersed concentric feature. And it is very interesting that the intensity in the center of photocurrent FFTs image (Figure S14f) is slightly stronger than the dark current FFTs image. The FFTs analysis suggests that the photocurrent mapping exhibits closer relationship with the topographic mapping compared with dark current mapping. As mentioned above, excitons tend to separate more efficiently at the edges of a perovskite crystal, and then the 
1 the perovskite as shown in Figure S12, which makes the profile of perovskite crystal appear

2 clearer. Thus, the closer relationship between the photocurrent FFTs image and topographic

3 FFTs image further proves the photocurrent enhancement effect at grain boundaries.

4 Discussion the Effect of the Interfaces (Tip/MAPbI3, CdS/ITO). In order to study the

5 influence of the interfaces (tip/ $\mathrm{MAPbI}_{3}$ and $\mathrm{CdS} / \mathrm{ITO}$ ) on the charge carrier transport in $6 \mathrm{tip} / \mathrm{MAPbI}_{3} / \mathrm{CdS} / \mathrm{ITO}$ system, the work function (WF) of $\mathrm{CdS}$ and $\mathrm{MAPbI}_{3}$ were measured via

7 Kelvin probe force microscopy $(\mathrm{KPFM})$ as shown in Figure $\mathrm{S} 15$. The WF of the tip $\left(\Phi_{\mathrm{tip}}=4.90\right.$ eV) was calibrated against a graphite crystal (freshly peeled surface) and the WF of the sample was calculated using:

$$
\Phi_{\text {sample }}=\Phi_{\text {tip }}-\mathrm{V}_{\mathrm{CPD}}
$$

$11 \mathrm{~V}_{\mathrm{CPD}}$ is the potential difference between sample and tip, which can be obtained by analyzing the KPFM mapping. ${ }^{61}$ The WF of CdS and $\mathrm{MAPbI}_{3}$ was determined to be $4.71 \mathrm{eV}$ and $4.88 \mathrm{eV}$, respectively. Herein, the ITO electrode has a WF $\left(\Phi_{\text {ITO }}\right)$ of $\sim 4.7 \mathrm{eV}$. Thus, the $\Phi_{\mathrm{B}, \mathrm{MAPbI} / \mathrm{Tip}}$ $\left(\Phi_{\text {MAPbI } 3}-\Phi_{\text {Tip }}\right)$ and $\Phi_{\mathrm{B}, \mathrm{CdS} / \mathrm{ITO}}\left(\Phi_{\mathrm{CdS}}-\Phi_{\mathrm{ITO}}\right)$ is quite small, which makes the interfaces (tip/MAPbI $3, \mathrm{CdS} / \mathrm{ITO}$ ) have very weak effect on the carrier transport.

\section{CONCLUSION}

In summary, we demonstrated $\mathrm{MAPbI}_{3} / \mathrm{CdS}$ heterojunction photodetectors for the first time.

18 The resulting devices exhibit excellent performance including high current on/off ratio $19 \sim 1.13 \times 10^{5}$, detectivity of $\sim 9.79 \times 10^{10}$ Jones and PCE of up to $\sim 10.05 \%$. Moreover, the mechanisms of photocurrent generation and transport across the $\mathrm{MAPbI}_{3} / \mathrm{CdS}$ heterointerface

21 have been studied down to nanoscales via C-AFM and PC-AFM. Obtained results demonstrated 22 that the combination of $\mathrm{CdS}$ with $\mathrm{MAPbI}_{3}$ lead to a remarkably improved photodetector 23 performance, and lay the foundation for future work. 
Materials. Ammonium hydroxide, $\mathrm{NH}_{4} \mathrm{Cl}$, thiourea $\left(\mathrm{SC}\left(\mathrm{NH}_{2}\right)_{2}\right), \mathrm{CdCl}_{2}$, anhydrous

2 dimethylsulfoxide (DMSO) and N,N-dimethylformamide (DMF) were purchased from

3 Shanghai Aladdin Bio-Chem Technology Co., LTD. Methylamine Hydroiodide (MAI) and $\mathrm{PbI}_{2}$

4 were purchased from Xi'an Polymer Light Technology Corp, all the chemicals were used as

5 received without further purification.

6 Device Fabrication. Through CBD method, the uniform film of CdS was fabricated on ITO

7 substrates. ${ }^{62}$ The precursor solution including $\mathrm{NH}_{4} \mathrm{OH}(0.640 \mathrm{Mol} / \mathrm{L}), \mathrm{NH}_{4} \mathrm{Cl}(0.015 \mathrm{Mol} / \mathrm{L})$,

8 thiourea $\left(\mathrm{SC}\left(\mathrm{NH}_{2}\right)_{2}(0.003 \mathrm{Mol} / \mathrm{L})\right), \mathrm{CdCl}_{2}(0.002 \mathrm{Mol} / \mathrm{L})$ and deionized water was prepared

9 before deposition. Then the ITO substrate was placed in the solution vertically by a clamp as

10 shown in Figure 1a. Solution bath system was kept magnetically stirred and the temperature

11 was maintained at $80{ }^{\circ} \mathrm{C}$ by a hot plate. The deposition time was $5 \mathrm{~min}, 7 \mathrm{~min}, 9 \mathrm{~min}, 11 \mathrm{~min}$

12 and $13 \mathrm{~min}$, respectively. After the CBD process, the backside of the ITO was treated by dilute

13 hydrochloric acid, since the CdS on the backside can block the light path and decreased the

$14 \mathrm{PCE}$ of $\mathrm{MAPbI}_{3} / \mathrm{CdS}$ photodetector. Then the $\mathrm{CdS}$ film was dipped in saturated $\mathrm{CdCl}_{2} / \mathrm{methanol}$

15 solution for 15 times. The deposited CdS was further gentally washed by DI water. After that,

16 thermal treatment was applied on the $\mathrm{CdS}$ thin film at $400{ }^{\circ} \mathrm{C}$ in $\mathrm{Ar}$ atmosphere for $20 \mathrm{~min}$. The

17 produced CdS thin film was characterized by Raman and XRD to confirm the sucessful 18 synthesis.

19 The $\mathrm{MAPbI}_{3}$ films were fabricated by a one-step-method. ${ }^{63,64}$ The $\mathrm{MAPbI}_{3}$ precursors 20 including $159 \mathrm{mg}$ MAI and $461 \mathrm{mg} \mathrm{PbI}_{2}$ were dissolved in $70 \mu \mathrm{L}$ anhydrous DMSO and 630 $21 \mu \mathrm{L}$ DMF. Then $120 \mu \mathrm{L}$ precursor solution was spun onto the CdS film at 2,500 rpm for $3 \mathrm{~s}$ and $224,500 \mathrm{rpm}$ for $25 \mathrm{~s}$, and $120 \mu \mathrm{L}$ toluene was dropped on the sample at $10 \mathrm{~s}$ quickly during the 23 spin-coating. After that, thermal treatment was applied on the sample at $82{ }^{\circ} \mathrm{C}$ for $25 \min$.

24 Finally, the gold counter electrodes were deposited by thermal evaporation. 
Characterizations. The PC-AFM and C-AFM experiments were carried out by BRUKER

2 DIMENSION ICON multi-function atomic force microscope, as illustrated in Figure 7a. All

3 images were scanned with an image resolution of $512 \times 512$ pixels. While, the C-AFM and PC-

4 AFM measurement is taken by peak force TUNA mode that provides direct, precise force

5 control and eliminate lateral force, enabling routine high sensitivity and high resolution current

6 imaging. In this mode, the current measurement is taken when the tip is contact with the sample

7 with a constant force $(150 \mathrm{nN}$, the maximum force between the tip and sample) for particular scanning area. The laser (405 nm) purchased from Changchun New Industries Optoelectronics Technology Co. Ltd. was used as the illumination light source. NanoScope-Analysis software package was used to process AFM images and generate FFT images.

The noise current of the devices was measured using a lock-in amplifier (Stanford Research System, SR830). During the measurement, a grounded metal box was used to keep the device in dark and reduce the noise produced by the electromagnetic interference. The PCE shown in Figure 4f was obtained by Enlitech QE-R3011. XRD measurements were carried out by Rigaku D/MAX-2500. SEM images were taken by a JEOL JSM 6700F field emission scanning electron microscope. The thickness of CdS and $\mathrm{MAPbI}_{3}$ layer were determined by the cross section SEM image of the prepared thin film.

\section{ASSOCIATED CONTENT}

\section{Supporting Information}

21 The Supporting Information is available free of charge on the

\section{ACS Publications website at DOI:}

Photograph of the photodetectors. SEM images of $\mathrm{CdS}$ film and $\mathrm{MAPbI}_{3}$ film. I-V curves of the $\mathrm{MAPbI}_{3} / \mathrm{CdS}$ heterojunction photodetector and the $\mathrm{MAPbI}_{3}$-only photodetector. I- $\mathrm{V}$ curves of the CdS-only photodetector. Discussion of noise current and noise equivalent power. 
1 Optimize the thickness of $\mathrm{CdS}$ and $\mathrm{MAPbI}_{3}$ layers. Noise current spectra of $\mathrm{MAPbI}_{3} / \mathrm{CdS}$

2 photodetector. Photocurrent, photoresponsivity and detectivity of the $\mathrm{MAPbI}_{3} / \mathrm{CdS}$

3 photoconductor under $1.5 \mathrm{~V}$. Detectivity of $\mathrm{MAPbI}_{3} / \mathrm{CdS}$ based photodetector under light

4 wavelength from $300 \mathrm{~nm}$ to $800 \mathrm{~nm}$. Dark current mappings. Photocurrent mappings.

5 Photoresponse mappings. Estimation of effective contact area. 2D FFTs images. Surface

6 potential image.

7 AUTHOR INFORMATION

8 Corresponding Author

9 *E-mail: Yumeng.shi@szu.edu.cn, henan.li@ szu.edu.cn, thomas.anthopoulos@kaust.edu.sa.

10 ORCID

11 A-7349-2012

12 Notes

13 The authors declare no competing financial interest.

14 ACKNOWLEDGEMENTS

15 We acknowledge the support from the Science and Technology Innovation Commission of 16 Shenzhen(JCYJ20170817100111548,JCYJ20170817101100705, ZDSYS201707271014468);

17 National Natural Science Foundation of China (Grant No. 21603192); the National Natural

18 Science Foundation of China (Grant No. 51602200, 61874074) and the (Key) Project of 19 Department of Education of Guangdong Province (Grant No. 2016KZDXM008). This project 20 was partially supported by Shenzhen Peacock Plan (Grant No. KQTD2016053112042971). 21 T.D.A. and C.M. are greatfull to King Abdullah University of Science and Technology 22 (KAUST) for financial support..

\section{References}

24 (1) Lu, H.; Tian, W.; Cao, F.; Ma, Y.; Gu, B.; Li, L. A Self-Powered and Stable All-Perovskite Photodetector-Solar Cell Nanosystem. Adv. Funct. Mater. 2016, 26, 1296-1302. 
1 (2) Xie, C.; You, P.; Liu Z.; Li, L.; Yan, F. Ultrasensitive Broadband Phototransistors Based on Perovskite/Organic-Semiconductor Vertical Heterojunctions. Light: Sci. Appl. 2017, 6, e17023.

(3) Green, M. A.; Ho-Baillie, A.; Snaith, H. J. The Emergence of Perovskite Solar Cells. Nat. Photonics. 2014, 8, 506-514.

(4) Zhao, Y.-C.; Zhou, W.-K.; Zhou, X.; Liu, K.-H.; Yu, D.-P.; Zhao, Q. Quantification of Light-Enhanced Ionic Transport in Lead Iodide Perovskite Thin Films and Its Solar Cell Applications. Light: Sci. Appl. 2017, 6, e16243.

(5) Haque, M. A.; Sheikh, A. D.; Guan, X. ; Wu, T. Metal Oxides as Efficient Charge Transporters in Perovskite Solar Cells. Adv. Energy Mater. 2017, 7, 1602803.

(6) Li, J.; Zhao, M.; Zhao, C.; Jian, H.; Wang, N.; Yao, L.; Huang, C.; Zhao, Y.; Jiu, T. Graphdiyne-Doped P3CT-K as an Efficient Hole-Transport Layer for $\mathrm{MAPbI}_{3}$ Perovskite Solar Cells. ACS Appl. Mater. Interfaces. 2019, 11, 2626-2631.

(7) Zhu, H.; Huang, B.; Wu, S.; Xiong, Z.; Li, J.; Chen, W. Facile Surface Modification of $\mathrm{CH}_{3} \mathrm{NH}_{3} \mathrm{PbI}_{3}$ Films Leading to Simultaneously Improved Efficiency and Stability of Inverted Perovskite Solar Cells. J. Mater. Chem. A. 2018, 6, 6255-6264.

(8) Wang, X.; Liu, H.; Zhou, F.; Dahan, J.; Wang, X.; Li, Z.; Shen, W. Temperature GradientInduced Instability of Perovskite via Ion Transport. ACS Appl. Mater. Interfaces. 2018, 10, $835-844$.

(9) Barrows, A. T.; Pearson, A. J.; Kwak, C. K.; Dunbar, A. D. F.; Buckley, A. R.; Lidzey, D. G. Efficient Planar Heterojunction Mixed-Halide Perovskite Solar Cells Deposited via Spray-Deposition. Energy. Environ. Sci. 2014, 7, 2944-2950.

(10) AbdollahiNejand, B.; Gharibzadeh, S.; Ahmadi, V.; Shahverdi, H. R. New Scalable ColdRoll Pressing for Post-Treatment of Perovskite Microstructure in Perovskite Solar Cells. J. Phys. Chem. C. 2016, 120, 2520-2528.

(11)Hwang, K.; Jung, Y.-S.; Heo, Y.-J.; Scholes, F. H.; Watkins, S. E.; Subbiah, J.; Jones, D. 
J.; Kim, D.-Y.; Vak, D. Toward Large Scale Roll-to-Roll Production of Fully Printed Perovskite Solar Cells. Adv. Mater. 2015, 27, 1241-1247.

(12)Deng, Y.; Wang, Q.; Yuan, Y.; Huang, J. Vividly Colorful Hybrid Perovskite Solar Cells by Doctor-Blade Coating with Perovskite Photonic Nanostructures. Mater. Horiz. 2015, 2 , $578-583$

(13)Kim, J. H.; Williams, S. T.; Cho, N.; Chueh, C.-C.; Jen, A. K.-Y. Enhanced Environmental Stability of Planar Heterojunction Perovskite Solar Cells Based on Blade-Coating. Adv. Energy Mater. 2015, 5, 1401229.

(14)Razza, S.; Di, G. F.; Matteocci, F.; Cinà, L.; Palma, A. L.; Casaluci, S.; Cameron, P.; D’Epifanio, A.; Licoccia, S.; Reale, A. Perovskitesolar Cells and Large Area Modules (100 $\mathrm{cm}^{2}$ ) Based on an Air Flow-Assisted $\mathrm{PbI}_{2}$ Blade Coating Deposition Process. J. Power Sources. 2015, 277, 286-291.

(15) Yang, Z.; Chueh, C.-C.; Zuo, F.; Kim, J. H.; Liang, P.-W.; Jen, A. K.-Y. High-Performance Fully Printable Perovskite Solar Cells via Blade-Coating Technique under the Ambient Condition. Adv. Energy Mater. 2015, 5, 1500328.

(16)Bao, C.; Yang, J.; Bai, S.; Xu, W.; Yan, Z.; Xu, Q.; Liu, J.; Zhang, W.; Gao, F. Photodetectors: High Performance and Stable All-Inorganic Metal Halide PerovskiteBased Photodetectors for Optical Communication Applications. Adv. Mater. 2018, 30, 1870288.

(17)Bao, C.; Chen, Z.; Fang, Y.; Wei, H.; Deng, Y.; Xiao, X.; Li, L.; Huang, J. Low-Noise and Large-Linear-Dynamic-Range Photodetectors Based on Hybrid-Perovskite Thin-SingleCrystals. Adv. Mater. 2017, 29, 1703209.

(18)Dong, J.; Wu, J.; Jia, J.; Fan, L.; Lin, Y.; Lin, J.; Huang, M. Efficient Perovskite Solar Cells Employing a Simply-Processed CdS Electron Transport Layer. J. Mater. Chem. C, 2017, 5, 10023.

(19)Hwang, I. ; Baek, M.; Yong, K. Core/Shell Structured $\mathrm{TiO}_{2} / \mathrm{CdS}$ Electrode to Enhance the 
Light Stability of Perovskite Solar Cells. ACS Appl. Mater. Interfaces. 2015, 7, 2786327870.

(20)Chen, C.; Zhai, Y.; Li, F.; Tan, F.; Yue, G.; Zhang, W.; Wang, M. High Efficiency $\mathrm{CH}_{3} \mathrm{NH}_{3} \mathrm{PbI}_{3}: \mathrm{CdS}$ Perovskite Solar Cells with $\mathrm{CuInS}$ 2 as the Hole Transporting Layer. $J$. Power. Sources. 2017, 341, 396-403.

(21)Liu, M.; Johnston, M. B.; Snaith, H. J. Efficient Planar Heterojunction Perovskite Solar Cells by Vapour Deposition. Nature. 2013, 501, 395-398.

(22)Fang, H.-H.; Wang, F.; Adjokatse, S.; Zhao, N.; Even, J.; Loi, M. A. Photoexcitation Dynamics in Solution-Processed for Mamidinium Lead Iodide Perovskite Thin Films for Solar Cell Applications. Light: Sci. Appl. 2016, 5, e16056.

(23)Zhao, Y.; Zhao, Y.; Zhou, W.; Li, Q.; Fu, R.; Yu, D.; Zhao, Q. In Situ Cesium Modification at Interface Enhances the Stability of Perovskite Solar Cells. ACS Appl. Mater. Interfaces. 2018, 10, 33205-33213.

(24)Kim, H. S.; Lee, J. W.; Yantara, N.; Boix, P. P.; Kulkarni, S. A.; Mhaisalkar, S.; Gratzel, M.; Park, N. G. High Efficiency Solid-State Sensitized Solar Cell-Based on SubMicrometer Rutile $\mathrm{TiO}_{2}$ Nanorod and $\mathrm{CH}_{3} \mathrm{NH}_{3} \mathrm{PbI}_{3}$ Perovskite Sensitizer. Nano Lett. 2013, $13,2412-2417$

(25)Qin, P.; Tanaka, S.; Ito, S.; Tetreault, N.; Manabe, K.; Nishino, H.; Nazeeruddin, M. K.; Grätzel, M. Inorganic Hole Conductor-Based Lead Halide Perovskite Solar Cells with 12.4\% Conversion Efficiency. Nat.Commun. 2014, 5, 3834.

(26)Chen, H.-W.; Zhu, R.-D.; He, J.; Duan, W.; Hu, W.; Lu, Y. Q.; Li, M.-C.; Lee, S.-L.; Dong, Y.-J.; Wu, S.-T. Going Beyond the Limit of an LCD's Color Gamut. Light:Sci. Appl. 2017, 6, e17043.

(27)Burschka, J.; Pellet, N.; Moon, S. J.; Humphry-Baker, R.; Gao, P.; Nazeeruddin, M. K.; Gratzel, M. Sequential Deposition as a Route to High-Performance Perovskite-Sensitized Solar Cells. Nature. 2013, 499, 316-319. 
1 (28)Li, Z.; Li, J.; Ding, D.; Yao, H.; Liu, L.; Gong, X.; Tian, B.; Li, H.; Su, C.; Shi, Y. Direct

2 Observation of Perovskite Photodetector Performance Enhancement by Atomically Thin Interface Engineering. ACS Appl. Mater. Interfaces. 2018, 10, 36493-36504.

(29)Jie, J. S.; Zhang, W. J.; Jiang, Y.; Meng, X. M.; Li, Y. Q.; Lee, S. T. Photoconductive Characteristics of Single-Crystal CdS Nanoribbons. Nano Lett. 2006, 6, 1887-1892.

(30)Juarez-Perez, E. J.; Wußler, M.; Fabregat-Santiago, F.; Lakus-Wollny, K.; Mankel, E.; Mayer, T.; Jaegermann, W.; Mora-Sero, I. Role of the Selective Contacts in the Performance of Lead Halide Perovskite Solar Cells. J.Phys.Chem.Lett. 2014, 5, 680-685.

(31)S. Abe1.; J. J. Joos.; L. IDJ. Martin.; Z. Hens.; P. F. Smet. Hybrid Remote Quantum Dot/Powder Phosphor Designs for Display Backlights. Light:Sci. Appl. 2017, 6, e16271.

(32)Leijtens, T.; Eperon, G. E.; Pathak, S.; Abate, A.; Lee, M. M.; Snaith, H. J. Overcoming Ultraviolet Light Instability of Sensitized $\mathrm{TiO}_{2}$ with Meso-Superstructured Organometal Tri-Halide Perovskite Solar Cells. Nat. Commun. 2014, 4, 2885.

(33)Ito, S.; Tanaka, S.; Manabe, K.; Nishino, H. Perovskite Photovoltaic Integrated $\mathrm{CdS} / \mathrm{TiO}_{2}$ Photoanode for Unbiased Photoelectron Chemical Hydrogen Generation. ACS Appl. Mater. Interfaces. 2018, 10, 23766-23773.

(34)Hwang, I.; Yong, K. Novel CdS Hole-Blocking Layer for Photostable Perovskite Solar Cells. ACS Appl. Mater. Interfaces. 2016, 8, 4226-4232.

(35)Peng, H.; Sun, W.; Li, Y.; Yan, W.; Yu, P.; Zhou, H.; Bian. Z.; Huang, C.; HighPerformance Cadmium Sulphide-Based Planar Perovskite Solar Cell and the Cadmium Sulphide/Perovskite Interfaces. J. Photonics Energy. 2016, 6, 022002.

(36)Son, Y.; Wang, Q. H.; Paulson, J. A.; Shih, C.-J.; Rajan, A. G.; Tvrdy, K.; Kim, S.; Alfeeli, B.; Braazt, R.; Strano, M. Layer Number Dependence of $\mathrm{MoS}_{2}$ Photoconductivity Using Photocurrent Spectral Atomic Force Microscopic Imaging. ACS Nano. 2015, 9, 2843-2855.

(37)Son, Y.; Li, M.-Y.; Cheng, C.-C.; Wei, K.-H.; Liu, P.; Wang, Q. H.; Li, L.-J.; Strano, M. S. Observation of Switchable Photoresponse of a Monolayer $\mathrm{WSe}_{2}-\mathrm{MoS}_{2}$ Lateral 
Heterostructure via Photocurrent Spectral Atomic Force Microscopic Imaging. Nano Lett. 2016, 16, 3571-3577.

(38)MacDonald, G. A.; Yang, M.; Berweger, S.; Killgore, J. P.; Kabos, P.; Berry, J. J.; Zhu, K.; DelRio, F.W. Methylammonium Lead Iodide Grain Boundaries Exhibit DepthDependent Electrical Properties. Energy Environ. Sci. 2016, 9, 3642-3649.

(39)Li, J.-J.; Ma, J.-Y.; Ge, Q.-Q.; Hu, J.-S.; Wang, D.; Wan, L.-J. Microscopic Investigation of Grain Boundaries in Organolead Halide Perovskite Solar Cells. ACS Appl. Mater. Interfaces. 2015, 7, 28518-28523.

(40) Yun, J. S.; Ho-Baillie, A.; Huang, Shujuan.; Woo, S. H.; Heo, Y.; Seidel, J.; Huang, F.; Cheng, Y.-B.; Green, M. A. Benefit of Grain Boundaries in Organic-Inorganic Halide Planar Perovskite Solar Cells. J. Phys. Chem. Lett. 2015, 6, 875-880.

(41)Cao, H. H.; Wang, G.; Zhang, S.; Zhang, X.; Rabinovich, D. Growth and Optical Properties of Wurtzite-Type CdS Nanocrystals. Inorg. Chem. 2006, 45, 5103-5108.

(42)Petrov, A. A.; Pellet, N.; Seo, J.-Y.; Belich, N. A.; Kovalev, Y. D.; Shevelkov, A. V.; Goodilin, E. A.; Zakeeruddin, S. M.; Tarasov, A. B.; Graetzel, M. New Insight into the Formation of Hybrid Perovskite Nanowires via Structure Directing Adducts. Chem. Mater. 2017, 29, 587-594.

(43)Hu, X.; Zhang, X.; Liang, L.; Bao, J.; Li, S.; Yang, W.; Xie, Y. High-Performance Flexible Broad and Photodetector Based on Organo Lead Halide Perovskite. Adv. Funct. Mater. 2014, 24, 7373-7380.

(44)Sinton, R. A. Contactless Determination of Current-Voltage Characteristics and MinorityCarrier Lifetimes in Semiconductors from Quasi-Steady-State Photoconductance Data. Appl. Phys. Lett. 1996, 69, 2510.

(45)Ha, S. T.; Liu, X.; Zhang, Q.; Giovanni, D.; Sum, T. C.; Xiong, Q. Synthesis of OrganicInorganic Lead Halide Perovskite Nanoplate Lets: Towards High-Performance Perovskite Solar Cells and Optoelectronic Devices. Adv. Optical Mater. 2014, 2, 838-844. 
1 (46)Xu, Z.; Edgeton, A.; Costello S. Spatially Inhomogeneous Photoluminescence-Voltage Hysteresis in Planar Heterojunction Perovskite-Based Solar Cells. Appl. Phys. Lett. 2017, $111,223901$.

(47)Diroll, B. T.; Guo, P.; Schaller, R. D. Unique Optical Properties of Methylammonium Lead Iodide Nanocrystals below the Bulk Tetragonal-Orthorhombic Phase Transition. Nano Lett. 2018, $18,846-852$.

(48)Ji, Li.; Hsu, H.-Yi.; Lee, J. C.; Bard, A. J.; Yu, E. T. High-Performance Photodetectors Based on Solution-Processed Epitaxial Grown Hybrid Halide Perovskites. Nano Lett. 2018, $18,944-1000$

(49) Adinolfi, V.; Ouellette, O.; Saidaminov, M. I.; Walters, G.; Abdelhady, A. L.; Bakr, O. M.; Sargent, E. H. Fast and Sensitive Solution-Processed Visible-Blind Perovskite UV Photodetectors. Adv. Mater. 2016, 28, 7264-7268.

(50)Shi, D.; Adinolfi, V.; Comin, R.; Yuan, M.; Alarousu, E.; Buin, A.; Chen, Y.; Hoogland, S.; Rothenberger, A.; Katsiev, K.; Losovyj, Y.; Zhang, X.; Dowben, P. A.; Mohammed, O. F.; Sargent, E. H.; Bakr, O. M. Low Trap-State Density and Long Carrier Diffusion in Organo Lead Trihalide Perovskite Single Crystals. Science. 347, 519-522 (2015).

(51) Arora, N.; Dar, M. I.; Hinderhofer, A.; Pellet, N.; Schreiber, F.; Zakeeruddin, S. M.; Grätzel, M. Perovskite Solar Cells with CuSCN Hole Extraction Layers Yield Stabilized Efficiencies Greater than 20\%. Science. 358, 768-771 (2017).

(52)Shit, A.; Chal, P.; Nandi, A. K. Copolymers of Poly(3-Thiopheneacetic Acid) with Poly(3Hexylthiophene) as Hole-Transporting Material for Interfacially Engineered Perovskite Solar Cell by Modulating Band Positions for Higher Efficiency. Phys. Chem. Chem. Phys. 2018, 20, 15890-15900.

(53)Tong, G.; Song, Z.; Li, C.; Zhao, Y.; Yu, L.; Xu, J.; Jiang, Y.; Sheng, Y.; Shi, Y.; Chen, K. Cadmium-Doped Flexible Perovskite Solar Cells with a Low-Cost and Low-TemperatureProcessed CdS Electron Transport Layer. RSC Adv. 2017, 7, 19457-19463. 
1 (54)Ma, C.; Shi, Y. M.; Hu, W. J.; Chiu, M. H.; Liu, Z. X.; Bera, A.; Li, F.; Wang, H. Li, L. J.; $\mathrm{Wu}$, T. Heterostructured $\mathrm{WS}_{2} / \mathrm{CH}_{3} \mathrm{NH}_{3} \mathrm{PbI}_{3}$ Photoconductors with Suppressed Dark Current and Enhanced Photodetectivity. Adv. Mater. 2016, 28, 3683-3689.

(55)Fang, Y.; Huang, J. Resolving Weak Light of Sub-Picowatt Per Square Centimeter by Hybrid Perovskite Photodetectors Enabled by Noise Reduction. Adv. Mater. 2015, 27, 2804-2810.

(56)Lee, Y.; Kwon, J.; Hwang, E.; Ra, C. H.; Yoo, W. J.; Ahn, J. H.; Park, J. H.; Cho, J. H. High-Performance Perovskite-Graphene Hybrid Photodetector. Adv. Mater. 2015, 27, 4146.

(57)Zhang, Y.; Du, J.; Wu, X.; Zhang, G.; Chu, Y.; Liu, D.; Zhao, Y.; Liang, Z.; Huang, J. Ultrasensitive Photodetectors Based on Island-Structured $\mathrm{CH}_{3} \mathrm{NH}_{3} \mathrm{PbI}_{3}$ Thin Films. ACS Appl. Mater. Interfaces. 2015, 7, 21634-21638.

(58)Georgiadou, D. G.; Lin, Y.-H.; Lim, J.; Ratnasingham, S.; McLachlan, M. A.; Snaith, H. J.; Anthopoulos, T. D. High Responsivity and Response Speed Single-Layer Mixed-Cation Lead Mixed-Halide Perovskite Photodetectors Based on Nanogap Electrodes Manufactured on Large-Area Rigid and Flexible Substrates. Adv. Funct. Mater. 2019, 29, 1901371.

(59)Li, Y.; Xu, C. Y.; Zhen, L. Surface Potential and Interlayer Screening Effects of FewLayer $\mathrm{MoS}_{2}$ Nanoflakes. Appl. Phys. Lett. 2013, 102, 143110.

(60)Feng, J.; Gong, C.; Gao, H.; Wen, W.; Gong, Y.; Jiang, X.; Zhang, B.; Wu, Y.; Wu, Y.; Fu, H.; Jiang, L.; Zhang, X. Single-Crystalline Layered Metal-Halide Perovskite Nanowires for Ultrasensitive Photodetectors. Nat. Electronics. 2018, 1, 404-410.

(61)Zhang, Y-Z.; Yu K.; Wang G-P. Edge Effect on the Population of Free Carriers and Excitons in Single-Crystal $\mathrm{CH}_{3} \mathrm{NH}_{3} \mathrm{PbBr}_{3}$ Perovskite Nanomaterials. Adv. Electron. Mater. 2019, 5, 1900216. 
1 (62)Sharma, I.; Mehta, B. R. Optical Properties and Band Alignments in ZnTe

2 Nanoparticles/MoS 2 Layer Hetero Interface Using SE and KPFM Studies. Nanotechnology. 2017, 28, 445701 .

4 (63)Chun, S.; Jung, Y.; Kim, J.; Kim, D. The Analysis of CdS Thin Film at the Processes of Manufacturing CdS/CdTe Solar Cells. J. Cryst. Growth. 2011, 326, 152-156.

(64)Zheng, X.; Chen, B.; Dai, J.; Fang, Y.; Bai, Y.; Lin, Y.; Wei, H.; Zeng, C. X.; Huang, J. Defect Passivation in Hybrid Perovskite Solar Cells Using Quaternary Ammonium Halide Anions and Cations. Nat. Energy. 2017, 2, 17102.

(65)Wu, Y.; Yang, X.; Chen, W.; Yue, Y.; Cai, M.; Xie, F.; Bi, E.; Islam, A.; Han, L. Perovskite Solar Cells with $18.21 \%$ Efficiency and Area over $1 \mathrm{~cm}^{2}$ Fabricated by Heterojunction Engineering. Nat. Energy. 2017, 1, 16148. 
Table Of Contents (TOC)

9

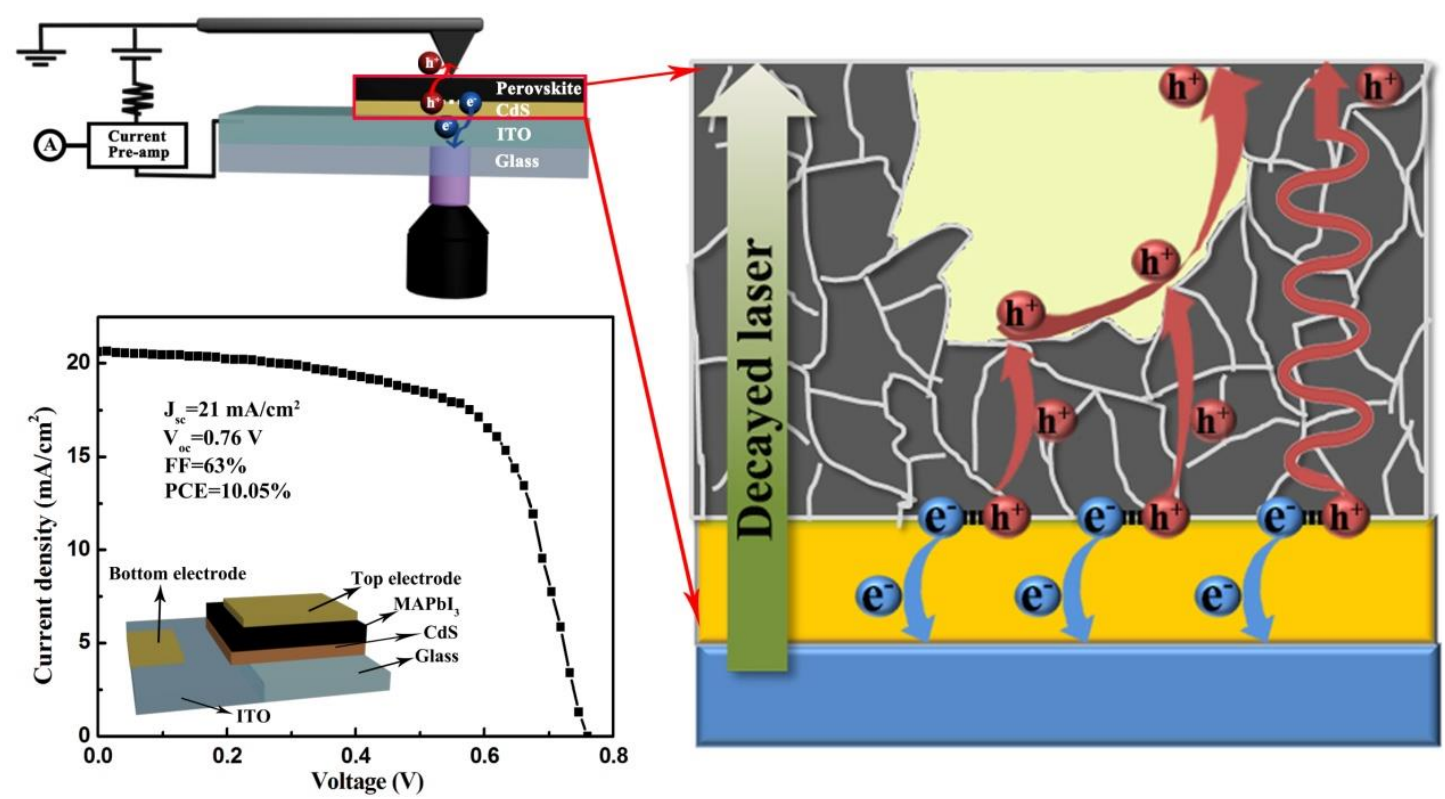

